\title{
O RELACIONAMENTO COMO ESTRATÉGIA DE FORTALECIMENTO DA REPUTAÇÃO CORPORATIVA: O CASO COCA-COLA ZERO
}

\author{
The relationship as a strategy for strengthening corporate reputation: the case coca-cola \\ zero
}

\section{La relación como estrategia para el fortalecimiento de la reputación corporativa: el caso coca-cola zero}

\author{
Tânia Oliveira Pereira ${ }^{1}$
}

\section{Resumo}

A proposta deste artigo é refletir sobre o conceito de reputação corporativa como subproduto do comportamento organizacional e da qualidade do relacionamento entre a organização e seus públicos, segundo Grunig e Kim (2011). O texto apresenta a estratégia de customização do rótulo da Coca-Cola Zero como uma forma de estreitar o relacionamento com seus públicos a partir de uma sondagem no Facebook, mídia social cuja principal plataforma é o relacionamento. Os dados obtidos demonstram uma forte interação dos públicos com a marca, tornando as embalagens customizadas um objeto de desejo.

Palavras-chave: reputação corporativa, relacionamento, comunicação, coca-cola zero.

\begin{abstract}
The purpose of this paper is to discuss the concept of corporate reputation as a byproduct of organizational behavior and the quality of the relationship between the organization and its publics, according to Grunig and Kim (2011). The paper presents the strategy of customizing the label of Coca-Cola Zero as a way to strengthen the relationship with its audiences from a poll on Facebook, social media whose main platform is the relationship. The data demonstrate a strong interaction of the public with the brand, making custom packaging an object of desire.
\end{abstract}

Keywords: corporate reputation, relationships, communication, coca-cola zero.

\footnotetext{
${ }^{1}$ Mestranda do Programa de Pós-Graduação em Ciências da Comunicação na Universidade de São Paulo. Pósgraduada em Gestão Estratégica em Comunicação Organizacional e Relações Públicas (2011) e graduada em Comunicação Social - Relações Públicas (2007), ambas pela Escola de Comunicações e Artes da Universidade de São Paulo. E-mail: tania.pereira@usp.br / Telefone: (11) 97258-4969
} 
O relacionamento como estratégia de fortalecimento da reputação corporativa: o caso coca-cola zero

de Tânia Oliveira Pereira

\section{Resumen}

El propósito de este trabajo es discutir el concepto de reputación corporativa como un subproducto de comportamiento organizacional y la calidad de la relación entre la organización y sus públicos, de acuerdo con Grunig y Kim (2011). El documento presenta la estrategia de personalizar la etiqueta de Coca-Cola Zero como una forma de fortalecer la relación con sus públicos a partir de una encuesta en Facebook, medios de comunicación social, cuya principal plataforma es la relación. Los datos demuestran una fuerte interacción del público con la marca, haciendo empaque a la medida de un objeto de deseo.

Palabras-clave: Reputación Corporativa, Relaciones, Comunicación, Coca-Cola Zero.

\section{INTRODUÇÃO}

Nas últimas duas décadas, a reputação passou a ser uma das mais importantes vantagens competitivas que uma empresa pode ter. Autores como Fombrun (1996) e Thevissen (2002) definiram a reputação como um ativo construído pelas organizações ao longo do tempo, mais importante até que o próprio produto ou serviço. Desta forma, manter e gerenciar esse ativo tem sido reforçado pelos pesquisadores para valorizar a performance das organizações. Segundo Fombrun e Shanley (1990), desde o início dos anos 1990 os investidores passaram a valorizar a reputação positiva das empresas ao decidirem pela compra de determinadas ações, assim como os consumidores começaram a pagar preços mais altos pelos produtos e os empregados passaram a preferir trabalhar em empresas reconhecidas por sua boa reputação. Com isso, os consumidores estão cada vez mais interessados em conhecer as organizações, suas “causas e propósitos", além de buscar informações sobre a qualidade e o custo-benefício dos produtos e serviços que adquirem. A reputação passou então a ser uma dimensão com prestígio em um cenário em que

se elas [as organizações] competem pela monopolização da atenção de seus públicos, se disputam sua admiração, se buscam com eles o alinhamento de interesses e se desejam conquistar a sua lealdade, precisam também incorporar novos diferenciais que influenciem positivamente a percepção que esses mesmos públicos delas têm. Qualidade de produtos, serviços e atendimento, aliada a uma boa política de preços, relacionamentos simétricos e sustentabilidade, são fatores decisivos para a consolidação de uma boa reputação, uma vez que já se foi o tempo em que os fatores próprios da lógica econômica, por si só, bastavam. (GRUNIG; FERRARI; FRANÇA 2011: 141). 
O relacionamento como estratégia de fortalecimento da reputação corporativa: o caso coca-cola zero

de Tânia Oliveira Pereira

Neste contexto de valorização da reputação, as organizações estão adquirindo a consciência de que já não conseguem mais controlar a maneira como seus discursos serão recebidos e interpretados pelos receptores, mas reconhecem esse ativo como um atributo de grande importância (IASBECK 2009). Isso porque seus discursos não são mais aceitos em sua totalidade pelos públicos, uma vez que estes agora assumiram o poder de suas decisões no momento da compra ou da escolha de um produto ou serviço. Os modelos de comunicação de mão única já não respondem mais totalmente às expectativas dos públicos com os quais as organizações se relacionam - seja porque o comportamento organizacional está em xeque ou porque os públicos estão mais organizados e conscientes de seus direitos e desejos (GRUNIG; FERRARI; FRANÇA 2011).

Para esta reflexão foi considerada a campanha "Descubra a sua Coca-Cola Zero", lançada em agosto de 2012, que colocou no mercado uma edição limitada da bebida na qual os rótulos foram customizados e estampados com nomes de consumidores, como Thiago, Carlos e Ana. O $b_{z z} z^{2}$ gerado pela campanha, tanto nos pontos de venda como nas mídias sociais despertou o desejo de estudar o relacionamento da marca Coca-Cola Zero com seu público consumidor decorrente desta campanha.

O presente documento pretende refletir sobre o conceito de reputação corporativa como subproduto dos comportamentos e relacionamentos organizacionais, segundo a linha de pesquisa de Grunig e Kim (2011). Está estruturado da seguinte forma: primeiro são apresentados conceitos de identidade, imagem e reputação corporativa, seguidos pela metodologia aplicada à sondagem, um breve panorama da marca Coca-Cola, o caso da campanha Descubra a sua Coca-Cola Zero e, por fim, são expostas as considerações finais do estudo.

\section{REPUTAÇÃO CORPORATIVA E OUTROS CONCEITOS}

O surgimento das novas tecnologias revolucionou a comunicação e alterou profundamente a forma dos relacionamentos organizacionais. A comunicação ganhou novos atores na contemporaneidade, em um cenário em que todos são produtores de conteúdo em potencial, graças ao advento da internet, dos aparelhos portáteis e das mídias sociais. E esse incessante avanço tecnológico, intensificado no início deste século, está possibilitando novas

${ }^{2} \mathrm{O}$ buzz marketing é uma estratégia para a disseminação de um produto ou serviço por meio da cadeia de consumidores. 
O relacionamento como estratégia de fortalecimento da reputação corporativa: o caso coca-cola zero

de Tânia Oliveira Pereira

formas de interação e gerando gradativamente mudanças comportamentais, inclusive nas organizações. Estas precisam rapidamente se adaptar a essa realidade mais colaborativa, a fim de aumentar o vínculo com seus públicos e fortalecer os seus relacionamentos.

Os públicos estão valorizando cada vez mais as organizações que demonstram um comportamento adequado, com discurso e atitude coerentes. Por isso, a compreensão do papel das relações públicas é essencial para o desenvolvimento de práticas apropriadas a essa nova conjuntura. Quando se fala em Coca-Cola, por exemplo, as pessoas associam à marca algumas percepções que têm a seu respeito, geradas a partir de estímulos recebidos anteriormente (CARVALHO; HAUBRICH 2010). E, devido a essa experiência prévia com as marcas, a identidade, a imagem e a reputação não raro são confundidas entre si pela diversidade de conceitos disponíveis, pois, "apesar da extensa literatura sobre o tema, nenhuma definição universalmente aceita pode ser atribuída [...] uma vez que os conceitos ainda permanecem rodeados por ambiguidades e falta de clareza" (ABRATT 1989 apud ALMEIDA 2009: 227). Para esse estudo foram utilizadas definições de autores com relevância na literatura especializada para os conceitos de identidade, imagem e reputação, que trazem perspectivas interessantes para o melhor entendimento dessa tríade da comunicação, que impacta cada vez mais diretamente os negócios de uma organização.

A identidade é um conceito complexo, pois, ao mesmo tempo em que ela é única "por se tratar de uma só organização, é vista, vivida e praticada por indivíduos com percepções, visões e perspectivas distintas, que vão construindo seus significados e res(significando-os) em um ambiente cultural exposto.” (ALMEIDA 2009: 217). Já Argenti (2006: 80) define a identidade como "a manifestação visual de sua realidade, [...] transmitida a partir do nome, logomarca, lema, produtos, serviços, instalações, folheteria, uniformes e todas as outras peças que possam ser exibidas, criadas pela organização [grifo do autor] e comunicadas a uma grande variedade de públicos”. Então, se a identidade é única, definida e controlada pela organização e construída a partir das mensagens por ela emitidas, presume-se que haja um público para o qual essas mensagens sejam direcionadas. Há espaço, então, para um processo de interpretação desse conteúdo e criação de percepções, que darão origem à imagem. Em uma perspectiva crítica, Iasbeck (2009) assegura que,

por mais aguçada que possa ser nossa percepção, nada nos dará, de antemão, a certeza de que seremos entendidos na dimensão e na intensidade que gostaríamos. O fato de não sermos o "outro" reserva sempre uma dose incalculável e imprevisível de surpresas e sobressaltos, que não são neutralizados nem mesmo pelos mais sofisticados instrumentos (e "modelos") de 
O relacionamento como estratégia de fortalecimento da reputação corporativa: o caso coca-cola zero

de Tânia Oliveira Pereira

otimização do processo da comunicação. (IASBECK 2009: 26).

Uma vez que a organização define os elementos de sua identidade, a imagem não é algo que a empresa possa controlar, pois se forma na mente dos indivíduos e está baseada inteiramente em percepções, resultado dos relacionamentos que são estabelecidos. Para Iasbeck (2012: 1), “a imagem, gerada no ambiente da recepção, além de não depender exclusivamente das intenções dos emissores, resultam de processamentos complexos e subjetivos até serem configuradas nas pesquisas estatísticas de satisfação, opinião ou hábitos de consumo". Complementando, Almeida (2009: 228) afirma que "a formação da imagem é um processo subjetivo, único, relacionado à experiência individual e, ao mesmo tempo, somatório de sensações, percepções e inter-relações de atores sociais".

Por fim, a reputação corporativa, segundo a definição clássica de Fombrun (1996: 72, tradução nossa), "é uma representação da percepção das ações passadas e das perspectivas futuras que descrevem a atratividade da companhia para todos os seus públicos-chave em comparação aos seus principais concorrentes”. Complementando essa visão, Thevissen (2002) afirma que a reputação pode ser entendida como:

[...] um crédito de confiança adquirido pela organização, estando esse crédito associado a valores como um bom nome, familiaridade, boa vontade e reconhecimento. Uma reputação negativa, em contraste, pode significar crédito limitado ou até mesmo nenhum crédito nas relações com os stakeholder. (THEVISSEN 2002: 320). Tradução nossa.

Vale ressaltar que são as relações públicas que, na administração dos relacionamentos, interagem com os três conceitos descritos acima. Assim, Ferrari (2011: 158) afirma que "o conceito contemporâneo enfatiza que relações públicas é uma função corporativa, pois elas ajudam a organização a definir suas políticas de comunicação e de relacionamento com seus públicos a fim de responder aos seus interesses estratégicos”. Fruto dessa definição, cada vez mais empresas se valem da atividade para buscar estratégias que perenizem um bom relacionamento, uma vez que existe uma estreita relação entre relacionamento e reputação, pois acredita-se que

as relações públicas têm um efeito de longo prazo maior nos relacionamentos do que na reputação, e que reputações são um subproduto do comportamento da administração e da qualidade de relacionamentos entre a organização e seus públicos. Consequentemente, a atenção dada aos relacionamentos resultará fundamentalmente na melhoria da reputação da organização. A reputação, entretanto, não pode ser administrada diretamente, e só ocorre quando se cultivam os relacionamentos. (GRUNIG; FERRARI; FRANÇA 2011: 106). 
O relacionamento como estratégia de fortalecimento da reputação corporativa: o caso coca-cola zero

É bastante interessante essa visão inovadora dos autores de que a reputação é o resultado dos relacionamentos de uma organização e que não pode ser administrada diretamente, pois até então se considerava apenas que se tratava do comportamento anterior da empresa ao longo dos anos. Seguindo essa perspectiva mais moderna, Grunig e Kim (2011: 38, tradução nossa) defendem que as relações públicas são uma "atividade que afetam o comportamento das organizações e melhoram os relacionamentos entre as organizações e as partes interessadas", defendendo o papel estratégico das relações públicas na gestão das empresas. Nesta linha, os autores destacam dois paradigmas da área, o simbólico e o comportamental, sendo que o último centra-se na participação de executivos de comunicação na tomada de decisões, de tal maneira que eles possam ajudar a gerenciar o comportamento das organizações, e não apenas interpretá-lo para os seus públicos. Os estudiosos acreditam que as relações públicas mostram valor para a alta administração ao trazer a tona os problemas e mostrar as possíveis soluções, isso porque as relações públicas "educam e persuadem os públicos defendendo os interesses corporativos, ao mesmo tempo em que negociam com esses públicos quando há conflitos de interesses” (GRUNIG; KIM 2011: 41. Tradução nossa). Para Grunig e Kim (2011: 41. Tradução nossa), “conceitos como marca e reputação são de natureza simbólica: uma marca é o que a organização tenta fazer com que os stakeholders pensem a respeito da organização, enquanto a reputação é o que eles realmente pensam e falam sobre ela". Ou seja, o que as pessoas falam sobre a organização é importante e afeta o seu comportamento. No entanto, a maioria dos profissionais e estudiosos ainda defende o paradigma simbólico, acreditando que os discursos organizacionais e a mídia, por si só, fortalecem uma marca e criam reputação.

Contudo, um dos mais completos estudos na área realizados até hoje, o The Excellence Study ${ }^{3}$, liderado por Grunig (1992), conclui que,

[...] as relações públicas tornam uma organização mais eficaz quando identificam os públicos mais estratégicos da organização como parte de uma gestão estratégica e processos e conduz. programas de comunicação para cultivar relacionamentos duradouros com esses públicos. (GRUNIG; KIM 2011: 46).

\footnotetext{
${ }^{3}$ Para mais detalhes, consultar GRUNIG, James E.; GRUNIG, Larissa A.; DOZIER, David M. Excellent public relations and effective organizations: a study of communication management in three countries. [S.1.]: Routledge, 2002.
} 
O relacionamento como estratégia de fortalecimento da reputação corporativa: o caso coca-cola zero

de Tânia Oliveira Pereira

Nessa linha, cada vez mais as organizações compreendem que relacionamentos frágeis custam uma grande quantidade de dinheiro, resultado de processos, greves, boicotes aos produtos ou queda nas vendas; por isso o desenvolvimento e a manutenção de relacionamentos com os públicos estratégicos são tão importantes. Os autores defendem que as "reputações são moldadas a partir do comportamento organizacional, e as mensagens por si só não podem mudar a forma como os públicos interpretam esses comportamentos" (GRUNIG; KIM 2011: 48), suportados por resultados de pesquisas que confirmaram que os comportamentos organizacionais e os relacionamentos foram fortemente relacionados à reputação.

\section{METODOLOGIA APLICADA À SONDAGEM}

Foi possível reunir uma grande quantidade de material sobre a campanha "Descubra a sua Coca-Cola Zero" a partir de uma pesquisa realizada na internet por meio do mecanismo de busca do Google (YAMAOKA, 2005). Para obter maior precisão e filtrar o excesso de informação disponível na rede, estruturamos um plano de busca fazendo uso dos operadores booleanos "AND" e "OR", além do recurso de delimitação por aspas. Após a identificação dos conceitos desejados para a pesquisa, foram listadas as palavras-chave correspondentes, inclusive as marcas envolvidas: "Coca-Cola" OR "The Coca-Cola Company"; "Coca-Cola Zero" OR "Diet Coke"; "Share a Coke" AND “Australia"; "Descubra a sua Coca-Cola Zero"; "latinha" AND "nome" AND "Coca-Cola"; "reputação" AND "Coca-Cola" e "comunicação" AND "Coca-Cola"; "customização" AND "reputação"; "relacionamento" AND "reputação". Foram consideradas as dez primeiras páginas de resultados apresentadas pelo Google, onde se determinou que a característica da informação devesse ser prioritariamente oriunda da imprensa nacional ou especializada. Tendo como suporte as informações encontradas nessa pesquisa realizada na internet, foi possível compreender melhor a história da companhia e da marca Coca-Cola Zero, bem como a origem e os desdobramentos da campanha Descubra a Sua Coca-Cola Zero, o que subsidiou a sondagem posterior nas mídias sociais.

Em 2012, com 34,15\% dos acessos, o Facebook atingiu o primeiro lugar do ranking brasileiro de redes sociais e fóruns da Experian Hitwise e superou os 60 milhões de usuários, 
O relacionamento como estratégia de fortalecimento da reputação corporativa: o caso coca-cola zero

de Tânia Oliveira Pereira

se tornando o segundo maior mercado para a companhia, atrás apenas dos Estados Unidos ${ }^{4}$. Por isso, devido a sua representatividade no país e por ser essencialmente uma plataforma de relacionamento, o Facebook foi a mídia social escolhida para a sondagem realizada neste artigo. No período entre agosto e setembro de 2012, foram observadas a fan page $e^{5}$ da CocaCola Zero e as manifestações na rede de relacionamentos da autora, e na rede da sua rede, o que evidenciou a interação provocada pela marca por meio de sua estratégia de customização dos rótulos com o nome de pessoas. Os rótulos customizados despertaram o desejo mais do que o próprio produto, devido ao forte apelo provocado por algo intrinsecamente relacionado à identidade do consumidor, como o seu nome. E assim, mais do que apta a vender refrigerante diet, a empresa mostrou-se capaz de promover um forte buzz no mercado em torno de um de seus produtos, articulando uma campanha de comunicação para estimular relacionamentos que, quando bem administrados, fortalecem a reputação.

\section{BREVE PANORAMA DA COCA-COLA}

Analisando inicialmente a história da companhia, um dos fatores determinantes para o seu sucesso parece ter sido suas estratégias de comunicação. Robert Woodruff, que esteve à frente da empresa durante 60 anos, vislumbrou muitas oportunidades de expansão, conquistando novos mercados com estratégias inovadoras para a época: a marca viajou com a equipe americana para as Olimpíadas de Amsterdã (1928); seu logotipo foi estampado em trenós de corridas de cachorro no Canadá e nas paredes das arenas de touros, na Espanha; abriu fábricas em países como Bélgica, Guatemala, Austrália e África do Sul; alavancou o desenvolvimento e a distribuição dos produtos por meio da embalagem com seis unidades e instalou geladeiras horizontais nos pontos de venda, entre outras inovações que tornaram a marca mais apreciada e conhecida. A visão de Woodruff de que uma Coca-Cola deveria estar sempre ao alcance das pessoas foi, aos poucos, se tornando uma realidade: em 2011 a The Coca-Cola Company foi a empresa que mais vendeu refrigerantes e sucos no mundo. Estimase que foram vendidas 1,7 bilhão de unidades de Coca-Cola por dia e que a marca estava presente em mais de 200 países no mundo (por questões políticas, Cuba, Mianmar e Coreia do

\footnotetext{
${ }^{4}$ Para saber mais, acesse: <http://www.cidademarketing.com.br/2009/n/9683/facebook-supera-orkut-no-brasilsegundo-a-experian-hitwise.html > e <http://exame.abril.com.br/tecnologia/noticias/brasil-supera-60-milhoes-deusuarios-no-facebook>.

${ }^{5}$ As fan pages (páginas de fãs) existem para que organizações e celebridades transmitam informações ao seus seguidores. Semelhante aos perfis pessoais, essas páginas podem ser aprimoradas com aplicativos que ajudem na comunicação e interação com o público.
} 
O relacionamento como estratégia de fortalecimento da reputação corporativa: o caso coca-cola zero

Norte são os únicos países em que o refrigerante não é comercializado). Em volume total, Estados Unidos, México, China e Brasil são os países que mais consomem os produtos da marca, sendo que o Brasil é o $12^{\circ}$ maior consumidor do refrigerante per capita, com 229 copos por habitante. E, para manter-se na liderança, a empresa planeja investir cerca de $\mathrm{R} \$ 25$ bilhões em todo o mundo até $2016^{6}$. A comprovação da solidez da marca aparece na mais recente Global RepTrak ${ }^{\mathrm{TM}} 100$, pesquisa do Reputation Institute ${ }^{7}$ que avaliou a reputação de 100 multinacionais nas 15 maiores economias do mundo. A The Coca-Cola Company foi considerada com uma reputação forte ao atingir 72,66 pontos do máximo de 100, apesar de seu produto principal, o refrigerante, estar em evidência por conta dos malefícios à saúde. Além disso, das sete dimensões avaliadas pela pesquisa (produtos e serviços, inovação, liderança ambiente de trabalho, desempenho, governança e cidadania), a Coca-Cola se destacou como TOP10 nas categorias liderança e desempenho.

Os investimentos em comunicação da Coca-Cola são expressivos. Para Jonathan Mildenhall vice-presidente global de marketing estratégico e comunicação criativa da companhia (AGUILHAR, 2012),

\footnotetext{
[...] nossos investimentos variam de acordo com cada marca e o país. Em alguns mercados ainda gastamos $80 \%$ do orçamento com campanhas para TV. Em outros, como no Reino Unido, apenas $30 \%$ do investimento vai para a TV, porque podemos usar a tecnologia mobile, as redes sociais e criar experiências para cativar os consumidores de forma mais efetiva. Nós não ditamos nenhuma forma de investimento aos mercados, porque cada escritório da CocaCola entende bem o seu consumidor e onde ele deveria estar - se é no Facebook, investindo em música ou fazendo outra coisa. O que nós tentamos é olhar para o total e gastar $70 \%$ do orçamento no que sabemos que funciona bem, $20 \%$ em coisas mais inovadoras, mas que funcionam, e $10 \%$ em ideias totalmente novas.
}

Se comparado ao seu orçamento total, os investimentos em ideias totalmente inovadoras podem ser considerados modestos, mas mantêm a Coca-Cola na vanguarda em ações de comunicação e marketing quando comparada a outras empresas.

$\mathrm{O}$ vice-presidente global da Coca-Cola afirma que sua missão é fazer a companhia dobrar de tamanho até 2020. Para tanto, a estratégia é aparentemente simples: fazer as pessoas do mundo inteiro "falar e falar e falar" sobre a Coca-Cola, de forma bem articulada e que cause impacto na percepção dos consumidores. Para ele,

\footnotetext{
${ }^{6}$ Confira 125 curiosidades sobre a Coca-Cola em: <http://www.terra.com.br/economia/infograficos/125curiosidades-coca-cola/>.

${ }^{7}$ O Reputation Institute é uma empresa especializada em gestão de reputação, imagem, marca e identidade, fundada em 1995 pelos professores Cees van Riel e Charles Fombrun. Mais informações em: www.reputationinstitute.com.
} 
O relacionamento como estratégia de fortalecimento da reputação corporativa: o caso coca-cola zero

de Tânia Oliveira Pereira

[...] as marcas deveriam estar prontas para ter uma conversa contínua com seu público, especialmente as voltadas para os consumidores jovens, que são muito ligados à tecnologia e comunicação móvel [...] Desenvolvemos campanhas com ideias tão contagiosas que não conseguimos prever onde elas vão parar. Elas podem parar no seu celular, na parede do seu banheiro, na discoteca, na quadra de futebol... Isso é importante, porque significa que a marca cede o controle para os consumidores. O meu trabalho é apenas inspirá-los para que eles queiram tomar esse controle.

Mildenhall deixa claro que, embora a empresa não se esquive das ações triviais, como manter uma conversa ativa e constante com seus seguidores nas mídias sociais, há espaço para a estruturação de campanhas mais complexas, desde que a imagem da Coca-Cola esteja sempre associada ao conceito de felicidade (AGUILHAR, 2012).

\section{DESCUBRA A SUA COCA-COLA ZERO}

Como uma evolução do conceito "Quanto mais zero, melhor", a Coca-Cola do Brasil lançou, em agosto de 2012, uma edição de rótulos customizados com os 150 nomes e apelidos mais comuns entre jovens adultos, como Thiago, Carlos e Ana. A ação faz parte da campanha "Descubra a sua Coca-Cola Zero", que disponibilizou as embalagens em mais de 500 mil pontos de venda do país, distribuídas em latas e garrafas de $600 \mathrm{ml}$ e de 2 litros. O projeto incluiu também filmes para TV, aplicativos e conteúdos nas mídias sociais (SIMON, 2012). A inspiração veio de uma campanha lançada na Austrália para a marca Coca-Cola e premiada nas categorias Outdoor, Promo \& Activations, Direct e Public Relations na edição de 2012 do Festival Cannes Lions ${ }^{8}$. O objetivo da ação era incentivar os jovens australianos a beber o refrigerante, pois uma pesquisa mostrou que, no mês anterior a sua realização, $50 \%$ desse público não havia consumido a bebida. Criou-se então uma campanha para reconectar as pessoas com a marca, por isso a busca do apelo pessoal. Na Austrália, como ilustra a Figura 1, foram escolhidos os 150 nomes mais populares no país para a customização dos rótulos, precedidos pela frase "Share a Coke with", demonstrando uma clara intenção da marca em estimular os relacionamentos com seu público.

\footnotetext{
${ }^{8}$ Para saber mais, acesse <http://www.canneslions.com/inspiration/past_winners_shortlists.cfm>
} 
O relacionamento como estratégia de fortalecimento da reputação corporativa: o caso coca-cola zero

de Tânia Oliveira Pereira

Fig. 1 - Rótulos de Coca-Cola customizados na Austrália

Fonte - Google Imagens

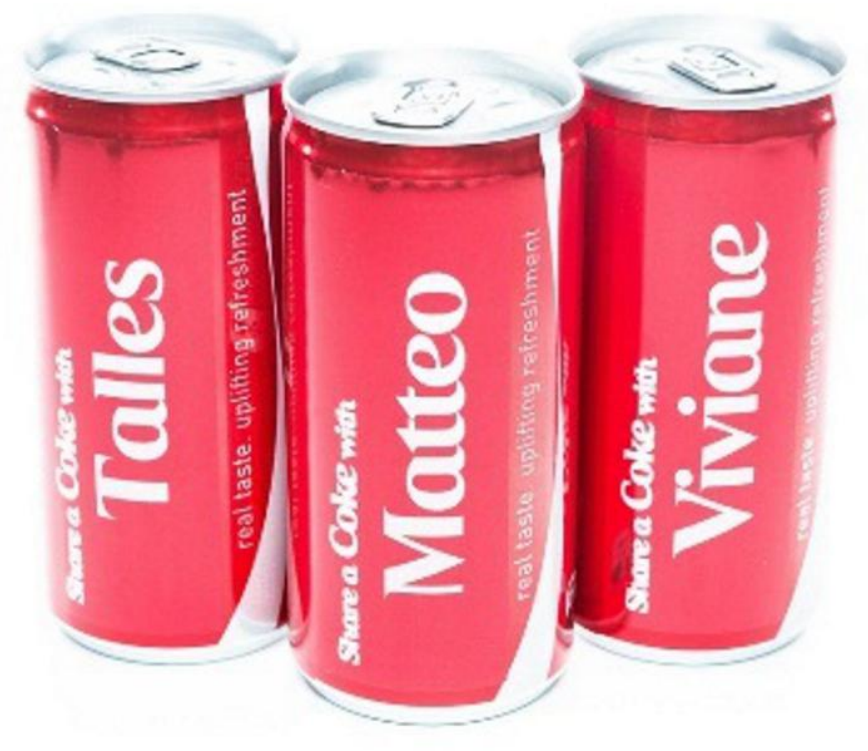

No Brasil a seleção de nomes foi ampliada e contou também com os apelidos mais comuns nos jovens, o que ajudou a ampliar a identificação com o público-alvo da bebida. Como a produção da Coca-Cola brasileira é descentralizada, os fabricantes do refrigerante receberam a lista completa e foram incluindo os nomes aos poucos em suas linhas de produção, tornando possível encontrar nomes diferentes nos pontos de venda (CARNEIRO 2012), o que aumentou o buzz da campanha, transformando as embalagens customizadas da bebida em um verdadeiro objeto de desejo, já que foi comum ver pessoas escolhendo latinhas nas gôndolas dos supermercados ou postando fotos da embalagem com seu nome no Facebook, onde a ação teve grande repercussão.

Até pouco tempo privilégio do mercado de luxo, os produtos sob medida têm sido a aposta também de grandes indústrias para conquistar o consumidor, conforme os exemplos a seguir (FREITAS 2012): (1) a Fiat lançou em 2010 um novo modelo do Uno, em que o cliente pode escolher entre dezenas de cores diferentes, além de personalizar o carro com adesivos e apliques; (2) é possível personalizar geladeiras e cooktops da linha Brastemp You, da Whirlpool, desde 2004; (3) na loja-conceito que a Havaianas mantém na Rua Oscar Freire, em São Paulo, o consumidor pode customizar seu par de sandálias, escolhendo o modelo e definindo a cor e os enfeites que serão colocados nas tiras. O professor da ESPM Marcos 
O relacionamento como estratégia de fortalecimento da reputação corporativa: o caso coca-cola zero

de Tânia Oliveira Pereira

Bedendo afirmou que os produtos "sob medida" atendem a um desejo dos consumidores, mas que não tendem a ter vida longa nas empresas:

O consumidor de produtos de massa, assim como o cliente do mercado de luxo, também gosta de se relacionar com uma marca que passa essa ideia de exclusividade. [...] Para as empresas de produtos de massa, essa é uma estratégia que atrapalha a linha de produção e tem um custo alto. As empresas usam esse modelo mais quando querem lançar um produto ou fazer uma promoção [...] Além disso, a maioria dos brasileiros ainda prefere produtos mais tradicionais, até porque o produto customizado costuma custar mais, e pouca gente está disposta a pagar. (FREITAS 2012).

Mas o caso da Coca-Cola Zero foi um pouco diferente, e talvez por isso tenha tido tanta repercussão: durante o período da campanha, não era necessário gastar nada a mais para ter uma embalagem personalizada dentro das 200 opções de nome disponibilizadas pela empresa.

Na sondagem realizada na fan page da Coca-Cola Zero no Facebook, entre agosto e setembro de 2012, foram encontrados 21 posts, sendo que 14 eram a respeito da campanha Descubra a Sua Coca-Cola Zero, conforme detalhado a seguir na Tabela 1. Os posts, que não tinham periodicidade, se valiam de uma linguagem informal e perguntas para estimular a interação, em uma clara tentativa de aproximação com os jovens. Juntos, os posts somaram 17.952 curtidas, 15.105 comentários e 11.183 compartilhamentos, mostrando uma interação significativa do público por meio dessa ferramenta. Vale ressaltar que foi considerada apenas a repercussão na fan page oficial da marca que, em setembro de 2012, tinha sido curtida por quase três milhões de pessoas. Não obstante, no mesmo período, a autora observou uma intensa repercussão da campanha por meio de posts de amigos em sua página pessoal do Facebook, e também da rede de sua rede; além de presenciar inúmeros consumidores escolhendo o produto exclusivamente pelo nome impresso em seu rótulo em bares, restaurantes e supermercados. 
O relacionamento como estratégia de fortalecimento da reputação corporativa: o caso coca-cola zero

de Tânia Oliveira Pereira

Tabela 1 - Posts sobre a campanha na fan page do Facebook

\begin{tabular}{|c|c|c|c|c|}
\hline Data & "Curtidas" & Comentários & Compartilhamentos & Post \\
\hline $01 / 08 / 2012$ & 788 & 170 & 990 & $\begin{array}{l}\text { O seu nome também pode estar numa latinha de Coca-Cola Zero. Entre em http://CokeURL.com/78rf e faça } \\
\text { a sua! }\end{array}$ \\
\hline 03/08/2012 & 912 & 1.881 & 322 & Que nome você gostaria de ver nas latas de Coca-Cola Zero? \\
\hline 06/08/2012 & 1.162 & 327 & 2.047 & Conhece alguma Carol? Marque ela na lata de Coca-Cola Zero! \\
\hline $10 / 08 / 2012$ & 1.179 & 736 & 1.243 & $\begin{array}{l}\text { Se você encontrou o seu nome numa dessas embalagens, pode correr para comprar a sua que ela já está } \\
\text { disponível! Só não esqueça de marcar a galera e fazer inveja pra todo mundo. :P }\end{array}$ \\
\hline $22 / 08 / 2012$ & 1.213 & 517 & 1.216 & $\begin{array}{l}\text { Uma Coca-Cola Zero com o seu nome pode estar te esperando. Confira a lista http://CokeURL.com/kce } 5 \text { e } \\
\text { corra para os pontos de venda. }\end{array}$ \\
\hline $23 / 08 / 2012$ & 1.315 & 657 & 934 & Quem aí já encontrou a sua Coca-Cola Zero? \\
\hline $24 / 08 / 2012$ & 1.529 & 887 & 1.102 & $\begin{array}{l}\text { Ficou chateado porque não encontrou seu nome nas embalagens de Coca-Cola Zero? Calma, ainda dá } \\
\text { tempo.; ) }\end{array}$ \\
\hline $25 / 08 / 2012$ & 1.136 & 574 & 788 & $\begin{array}{l}\text { Quem encontrou o nome aí embaixo tá todo engraçadão porque tem o nome nas embalagens de Coca-Cola } \\
\text { Zero. Pode admitir: Quem mais aí tá se achando e já contou pra todo mundo? :P }\end{array}$ \\
\hline $06 / 09 / 2012$ & 1.067 & 423 & 395 & $\begin{array}{l}\text { Agora todo mundo pode ter o nome numa garrafa de Coca-Cola Zero. Entre em http://CokeURL.com/54y3 } \\
\text { coloque seu nome e peça pra galera votar. Os } 50 \text { primeiros vão aparecer nas embalagens de } 600 \mathrm{ml} \text {. :) }\end{array}$ \\
\hline $11 / 09 / 2012$ & 1.507 & 4.939 & 197 & Qual nome você gostaria de ver nas embalagens de Coca-Cola Zero? Quanto mais ___ melhor! \\
\hline $13 / 09 / 2012$ & 1.148 & 236 & 579 & $\begin{array}{l}\text { Galera, não adianta pedir só pra mãe e pra namorada votar no site. Todo mundo vai ter que entrar nessa pro } \\
\text { seu nome aparecer nas novas embalagens. Entra lá: http://CokeURL.com } / 54 \mathrm{y} 3\end{array}$ \\
\hline $14 / 09 / 2012$ & 1.985 & 2.184 & 788 & $\begin{array}{l}\text { Hoje é o último dia pra votar nos nomes que você quer ver nas garrafas de Coca-Cola Zero. Depois não } \\
\text { adianta ficar de mimimi. Confira se o seu está entre os } 50 \text { primeiros: http://CokeURL.com/54y3 }\end{array}$ \\
\hline $26 / 09 / 2012$ & 2.038 & 587 & 231 & $\begin{array}{l}\text { Não encontrou o seu nome nas embalagens de Coca-Cola Zero? Fique ligado aqui na fan page que a partir } \\
\text { da semana que vem os quiosques para personalizar a sua latinha vão começar a rodar pelo país. Não perca }\end{array}$ \\
\hline $27 / 09 / 2012$ & 973 & 987 & 351 & $\begin{array}{l}\text { Confira os } 50 \text { novos nomes que estarão nas embalagens de } 600 \mathrm{ml} \mathrm{de} \mathrm{Coca-Cola} \mathrm{Zero} \mathrm{a} \mathrm{partir} \mathrm{da} \mathrm{segunda} \\
\text { quinzena de novembro! Fique ligado e procure a sua: http://CokeURL.com/y7yk }\end{array}$ \\
\hline
\end{tabular}

Curiosamente, em pesquisa com uma amostra de consumidores da região sul em 2010, Carvalho e Haubrich (2010: 13), afirmaram que "apesar de não ter sido lembrada pelos entrevistados, a Coca-Cola também tem atuação, com menor intensidade, nas mídias sociais como Orkut, Twitter, Facebook e YouTube, dentre outras. A fraqueza da atuação da marca nesses canais revela a perda de oportunidade de interação próxima junto aos seus diversos públicos". Então, se antes os consumidores tinham dificuldade de lembrar-se das ativações da marca nas mídias sociais, essa campanha parece ter alterado significativamente esse cenário, como mostram os números da Tabela 1.

Verificando os dados apresentados pela Tabela 1, no post de 06/08/2012, por exemplo, quando foi questionado quem conhecia alguma Carol, a resposta foi uma participação com expressivos 2.047 compartilhamentos. Também houve um grande pico de comentários em 11/09/2012, quando foi perguntado qual nome o consumidor gostaria de ver estampado na embalagem do produto. Essa repercussão reforça a aura de objeto de desejo das "latinhas", que se transformaram em muito mais que a embalagem de um refrigerante: tornaram-se objetos de decoração, artigo de coleção e suporte para declarações de amor e de amizade, como mostra a Figura 2. 
O relacionamento como estratégia de fortalecimento da reputação corporativa: o caso coca-cola zero

de Tânia Oliveira Pereira

Fig. 2 - Manifestações do público no Facebook

Fonte - https://www.facebook.com/cocacolazero
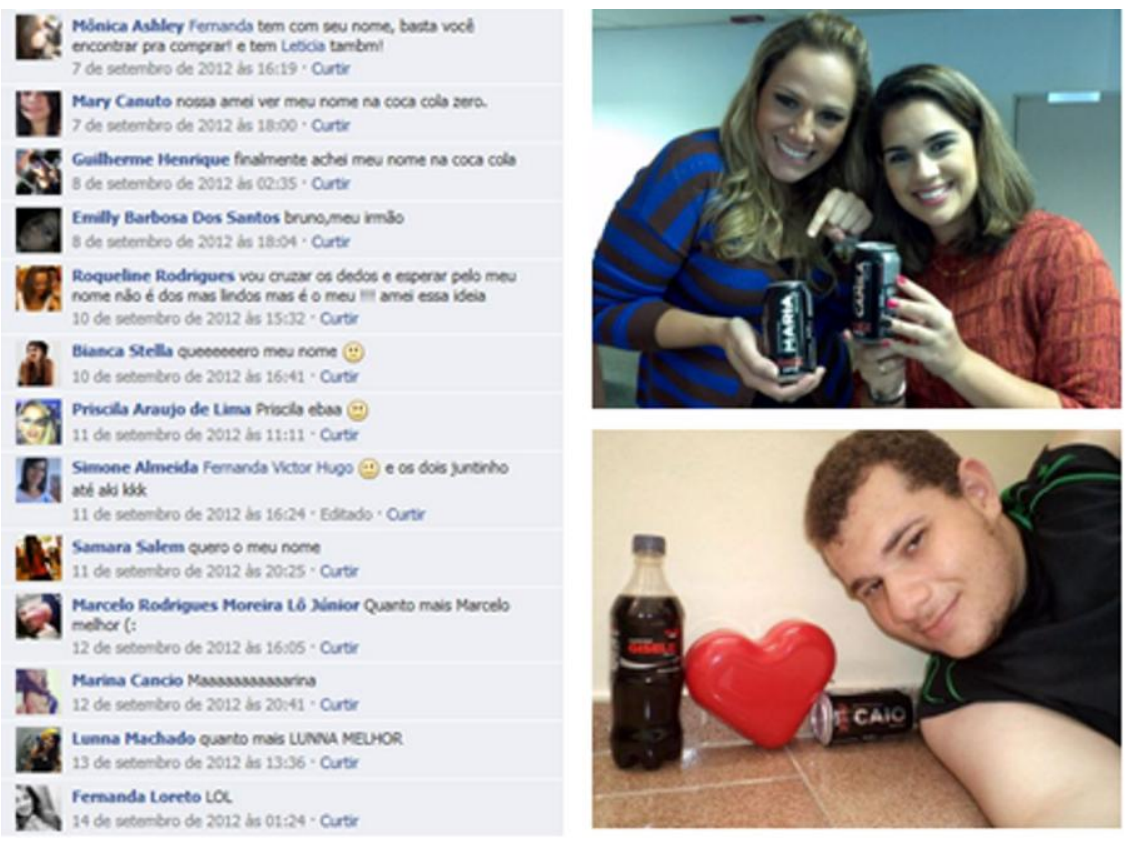

Sobre a repercussão da campanha Descubra a sua Coca-Cola Zero, Mildenhall (AGUILHAR, 2012) afirmou que,

Os brasileiros são viciados em redes sociais. Possuem mais amigos, mais plataformas e criam mais conversas na internet do que qualquer outro país. [...] Nosso trabalho é tornar as nossas redes sociais ainda mais compartilháveis. Nós acabamos de fazer um trabalho bonito com a Coca-Cola Zero [...] em que nossa equipe brasileira transformou um conceito criado pela CocaCola na Austrália em uma plataforma da Coca-Cola Zero no Brasil. É brilhante. E fazer as pessoas compartilharem essa experiência é incrível. Vocês amam as redes sociais e amam compartilhar.

Então, como estratégia para estimular ainda mais a interação e promover uma sensação de participação no público, o consumidor que não teve o nome entre os 150 selecionados pela empresa pode participar de uma votação promovida no Facebook, que escolheu 50 novos nomes para estampar os rótulos - como também já havia sido feito anteriormente na Austrália. Entre os nomes mais votados, ficou evidente a diversidade brasileira em rótulos como Sharlene, Hilanilson e Larielle. Mas esses nomes extras não bastaram e milhares de latas personalizadas foram impressas em quiosques itinerantes montados pela empresa em parceria com a Intel em shoppings de cidades como Brasília, São Paulo e Rio de Janeiro e latas virtuais foram criadas com o auxílio de um aplicativo 
O relacionamento como estratégia de fortalecimento da reputação corporativa: o caso coca-cola zero

de Tânia Oliveira Pereira

desenvolvido especialmente para a campanha no Facebook (CARNEIRO 2012), como mostra a Figura 3.

Fig. 3 - Aplicativo do Facebook para a customização de latas virtuais

Fonte - https://apps.facebook.com/descubracocacolazero/

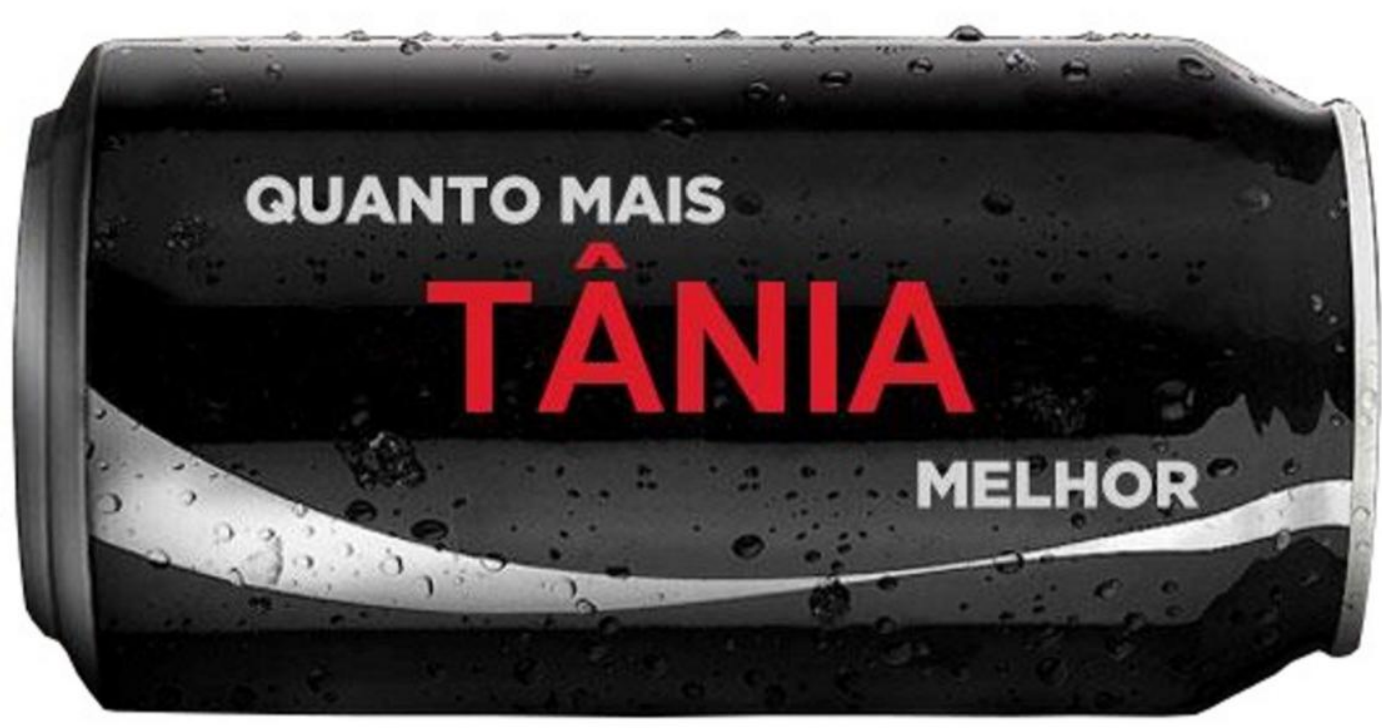

$\mathrm{Na}$ Austrália, onde foi concebida a ideia da customização dos rótulos, apenas três meses após o início da campanha, no verão de 2011, os resultados já eram expressivos ${ }^{9}$. O volume de Coca-Cola consumido aumentou 4\%, e as vendas do produto cresceram $3 \%$. Os acessos ao Facebook da Coca-Cola aumentaram espantosos $870 \%$, sendo o mais comentado do país e o $23^{\circ}$ do mundo, com US\$ 121 milhões ganhos em media impressions ${ }^{10}$. Também foram customizadas 378 mil latas em quiosques espalhados pelo país; os conteúdos de relações públicas alcançaram cerca de 14 milhões de pessoas e, por fim, o consumo geral aumentou em 5\%, e entre os jovens adultos, foco da campanha, $7 \%$.

No Brasil, a campanha continua sendo veiculada - agora explorando nomes de destinos turísticos - o que inviabiliza avaliar em profundidade os seus resultados neste trabalho e se houve impacto na reputação da marca. No entanto, um dado disponível para

\footnotetext{
${ }^{9}$ Para conhecer o caso australiano, acesse: $\langle\mathrm{http}: / / \mathrm{www}$.youtube.com/watch? $\mathrm{v}=21$ WzEdUd0o\&noredirect=1〉.

${ }^{10}$ Espécie de medida de engajamento gerado por "curtidas", comentários e compartilhamentos de uma fan page, tópico ou marca. Mais informações em: <http://mashable.com/2011/06/23/paid-earned-owned-media>.
} 
O relacionamento como estratégia de fortalecimento da reputação corporativa: o caso coca-cola zero

de Tânia Oliveira Pereira

comparação são os compartilhamentos de latas virtuais pelo Facebook entre os dois países. Apesar da diferença populacional ${ }^{11}$, após cerca de 90 dias do início da campanha, foram personalizadas 76 mil latas virtuais na Austrália e 4,3 milhões de latas no Brasil. Esse número, aproximadamente 56 vezes maior que o da Austrália, demonstra a boa aceitação da campanha no país e uma boa perspectiva para os resultados que ainda serão atingidos.

\section{CONSIDERAÇÕES FINAIS}

O objetivo deste artigo foi refletir sobre o conceito de reputação corporativa como subproduto do comportamento e dos relacionamentos organizacionais. Isso porque, uma tendência que se firma nitidamente na sociedade é a valorização cada vez maior das organizações que tenham um comportamento exemplar. E para que essa conduta seja percebida como exemplar é preciso muito mais que discursos organizacionais bem articulados. É preciso que as organizações estabeleçam relacionamentos duradouros e de qualidade com os seus públicos de interesse, pois relacionamentos bem administrados geram reputação positiva. Mas para isso, é preciso atrair a atenção desses públicos e desta forma ganham destaque as ações que promovem a interação e a colaboração, muitas delas viabilizadas com o suporte da tecnologia e, mais recentemente, das mídias sociais.

Por isso, destacamos nesse texto a campanha "Descubra a sua Coca-Cola Zero", lançada inicialmente na Austrália e depois adaptada para o Brasil. A ação reafirmou o posicionamento emocional da marca, em uma tentativa de criar vínculos com seu público, elemento fundamental nos relacionamentos. Certamente, personalizar os rótulos com uma variedade de 200 nomes não é uma ação capaz de criar um relacionamento duradouro, mas foi muito eficaz para gerar um buzz no mercado e atrair a atenção do público-alvo da campanha. Isso porque o rótulo do produto, estrategicamente customizado com nomes de pessoas, estimulou a interação e se transformou quase em uma extensão da personalidade do consumidor, tornando-se um verdadeiro objeto de desejo, como pode ser percebido com a repercussão diagnosticada na sondagem realizada no Facebook.

\section{REFERÊNCIAS BIBLIOGRÁFICAS}

\footnotetext{
${ }^{11} \mathrm{O}$ dado mais recente disponibilizado pelo Banco Mundial, de 2011, mostra que a Austrália tem uma população de 22.620.600 habitantes, enquanto o Brasil possui 196.655.014 habitantes.
} 
O relacionamento como estratégia de fortalecimento da reputação corporativa: o caso coca-cola zero

AGUILHAR, Ligia. Os segredos do marketing de sucesso da Coca-Cola. Época Negócios, São Paulo, 20 ago. 2012. Disponível em:

<http://epocanegocios.globo.com/Inspiracao/Empresa/noticia/2012/08/os-segredos-domarketing-de-sucesso-da-coca-cola.html>. Acesso em: 03 nov. 2012.

ALMEIDA, Ana Luisa de Castro. Identidade, imagem e reputação organizacional: conceitos e dimensões da práxis. In: KUNSCH, Margarida M. K. (Org.). Comunicação organizacional: linguagem, gestão e perspectivas. Vol. 2. São Paulo: Saraiva, 2009: 215-242.

ARGENTI, Paul A. Comunicação Empresarial. 4. ed. Rio de Janeiro: Campus, 2006.

CARNEIRO, Lucianne. Campanha da Coca-Cola Zero já rendeu quase 1,5 milhão de latas virtuais personalizadas. O Globo Online, Rio de Janeiro, 17 set. 2012. Disponível em:<http://oglobo.globo.com/economia/campanha-da-coca-cola-zero-ja-rendeu-quase15milhaode-latas-virtuais-personalizadas-6114273>. Acesso em: 03 nov. 2012.

CARVALHO, Cíntia; HAUBRICH, Gislene F. Da identidade à reputação: um estudo sobre a marca Coca-Cola. In: Congresso Brasileiro de Ciências da Comunicação, 33., 2010, Caxias do Sul. Anais eletrônicos. Caixas do Sul: UCS, set. 2010. Disponível em:<http://www.intercom.org.br/papers/

nacionais/2010/resumos/R5-3135-1.pdf> . Acesso em: 01 jul. 2012.

COCA-COLA Zero avança na customização. Meio \& Mensagem, São Paulo, 17 out. 2012. Disponível em:

<http://www.meioemensagem.com.br/home/marketing/noticias/2012/10/17/Coca-Cola-Zeroavanca-na-customizacao.html>. Acesso em: 03 nov. 2012.

FOMBRUN, Charles J. Reputation: realizing value from the corporate image. Boston: Harvard Business School Press, 1996.

.; SHANLEY, Mark. What's in a name? Reputation building and corporate strategy. Academy of Management Journal. Mississippi,v. 33, n. 2: 233-258, June 1990.

FREITAS, Aiana. Clientes agora põem nome em lata de Coca-Cola e escolhem cor especial de geladeira, fogão e carro. UOL, São Paulo, 15 ago. 2012. Disponível em: $<$ http://economia.uol.com.br/ultimasnoticias/redacao/2012/08/15/clientes-agora-poemnome-em-lata-de-coca-cola-e-escolhem-cor-de-geladeira-fogao-e-carro.jhtm>. Acesso em: 03 nov. 2012. 
O relacionamento como estratégia de fortalecimento da reputação corporativa: o caso coca-cola zero

de Tânia Oliveira Pereira

GRUNIG, James E., FERRARI, Maria Aparecida; FRANÇA, Fábio. Relações Públicas: teoria, contexto e relacionamentos. 2. ed., São Caetano do Sul: Difusão, 2011. .; KIM, Jeong-Nam. Actions speak louder than words. Insight Train, [S.1.], v. 1: 36-51, 2011.

IASBECK, Luiz Carlos Assis. Leituras da imagem: impressão, sensação, interpretação e opinião. In: Encontro Anual da Compós, 21., 2012, Juiz de Fora. Anais eletrônicos. Juiz de Fora: UFJF, jun. 2012. Disponível em:

$<$ http://www.compos.org.br/pagina.php?menu=8\&mmenu=0\&fcodigo=1858>. Acesso em: 26 jun. 2012. . Identidade organizacional e a construção dos discursos institucionais. In: KUNSCH, Margarida (Org.). Comunicação organizacional: linguagem, gestão e perspectivas. Vol. 2. São Paulo: Saraiva, 2009: 7-29.

ROSA, Mário. A reputação sob a lógica do tempo real. Organicom - Revista Brasileira de Comunicação Organizacional e Relações Públicas. São Paulo, a.4, n. 7: 58-69, 2007.

SIMON, Cris. Coca-Cola terá rótulos com nomes de consumidores. Portal Exame, São Paulo, 30 jul. 2012. Disponível em:

<http://exame.abril.com.br/marketing/galerias/embalagens/coca-cola-tera-rotulos-com-nomede-consumidores>. Acesso em 03 nov. 2012.

THEVISSEN, Frank. Belgium: corporate reputation in the eye of the beholder. Corporate Reputation Review. London, v. 4, n. 4: 318-326, winter 2002.

YAMAOKA, Eloi Juniti. O uso da internet. In: DUARTE, Jorge; BARROS, Antonio. Métodos e técnicas de pesquisa em comunicação. São Paulo: Atlas, 2005: 146-163.

Artigo submetido: 21/03/2013

Artigo aprovado: 26/08/2013 